'Politik und Religion', in: N. Konegen/P. Nitschke (eds.), Staat bei Hugo Grotius (Baden-Baden: Nomos Verlag 2005)

\title{
Hans Blom
}

\section{Hugo Grotius: Religion und Politik}

\section{Einleitung}

In diesem Kapitel soll versucht werden, Grotius als politischen Philosophen im wahrsten Sinne des Wortes zu betrachten. Sein Beitrag zur politischen Theologie und religiösen Politik wird hier nachgezeichnet, da Grotius die großen, doch noch immer kaum erkennbaren Fragen des 17. Jahrhunderts ansprach. Dabei stellen wir ihn gleichberechtigt neben andere große politische Philosophen des 17. Jahrhunderts, wie vor allem Hobbes, Spinoza, Pufendorf und Locke. Mit dieser Einführung zu einem Kapitel über Religion und Politik bei Grotius möchte ich meine Überzeugung zum Ausdruck bringen, dass die Verbindung zwischen Kirche und Staat oder, allgemeiner gesagt, die Politik der Religion, der direkteste Weg ist, seinen epochalen Beitrag zum politischen Selbstverständnis der modernen Welt zu beurteilen. Mein Ansatz besteht aus mehreren Analyseschichten. Zunächst gilt es - wie bei jedem politischen Philosophen - einen Kontext zu erörtern, zweitens eine Strategie aufzudecken und drittens schließlich ein philosophisches System darzustellen. In diese Abschnitte gliedert sich die folgende Beweisführung.

Im ersten Abschnitt analysiere ich den Kontext jener frühen Periode der Holländischen Republik, als Staatsbildung und Reformation miteinander einhergingen, die für Grotius’ Intellekt prägend war. Diese sehr interessante Phase der politischen und religiösen Entwicklung ist Gegenstand eingehender Forschung gewesen, ${ }^{1}$ krankt aber noch immer an einer disziplinären Aufsplitterung. Religions-, Politik- und Rechtshistoriker neigten dazu, getrennt vorzugehen, wobei die wichtigen Interdependenzen zwischen den erst in späteren Jahrhunderten getrennten Disziplinen übersehen wurden. Besonders eingehen werde ich auf die Bedeutung religiöser Debatten auf das politische Selbstverständnis und folglich auf das Wesen politischer Entwicklungen und Ideologien. Meine Kernaussage ist, dass der Inhalt der religiösen Debatten für das Verständnis der Essenz der politischen Entwicklungen und Ideologien entscheidend ist; d. h., die Fragen von Toleranz und Prädestination haben einen substantiellen Bezug zu den im Nachhinein rekonstruierten oranischen und republikanischen Fraktionen der holländischen Politik des frühen 17. Jahrhunderts. Begründen lässt sich diese Behauptung auch durch Grotius’ frühe Schriften, d. h. die ersten zwei Jahrzehnte seiner Autorschaft.

Vgl. u.a. Israel 1995, Prak 2002. 
Im zweiten Abschnitt decke ich Grotius’ intellektuelle Strategie auf. Dabei unterscheide ich zwischen den Schriften vor seiner Gefangenschaft auf Schloss Loevestein (1619-1621) und denen, die diese Periode reflektieren (Memorie, Apologetica, Waerheid, De imperio). Ein Kernpunkt wird die Darlegung der Gründe für Grotius offensichtliche Fehleinschätzung der politischen Lage in den 1610er Jahren sein. Die meisten Studien begnügen sich damit, dass Grotius und seine politischen Freunde (Johan van Oldenbarneveldt und die arminianisch ausgerichteten Regenten) politisch wie militärisch von Statthalter Moritz, Prinz von Oranien, und seinem erfolgreichen politischen Ränkespiel überlistet worden waren. Dieser nutzte die calvinistische Unzufriedenheit zur Vorantreibung seiner eigenen dynastischen und politischen Bestrebungen. Was war falsch oder was fehlte an den politischen Analysen von Grotius und Oldenbarneveldt?

Im letzten Teil des Kapitels greife ich diese Fragen in einem größeren Kontext wieder auf und versuche, die Kohärenz in Grotius’ frühen religiösen und politischen Schriften darzulegen. Seine politische Philosophie, so werde ich argumentieren, ist die erste in einer Reihe naturpolitischer Philosophien, die sich alle mit der inhärenten Beziehung zwischen Religion und Politik befassen - eine Reihe, zu der Petrus Cunaeus, Lambertus van Velthuysen, Pieter de la Court und Benedictus de Spinoza zählen. Nur am Rande werde ich eingehen auf die Unterschiede zwischen diesem holländischen Naturalismus und dem politischen Gedanken von Grotius’ Zeitgenossen: Hobbes, Locke und Pufendorf. Diese Übung versteht sich als ein Prolegomena zur integrierten Untersuchung Grotius’ späterer Schriften De jure belli ac pacis (1625), De veritate (1627), Annotationes (1641-44) und das merkwürdige De fato (1648), auf die wir nur kurz verweisen.

\section{Die Politik der Religion: Prophezeiung und Vorsehung}

Im letzten großen Kapitel des Parallelon (1601-3) erörtert Grotius Religion und Frömmigkeit. Im Einklang mit dem allgemeinen Tenor dieses etwas hagiographischen Textes, ${ }^{2}$ vergleicht Grotius die Religiosität der Griechen, Römer und Holländer. Nach einem Überblick über den allgemeinen Charakter der antiken griechischen und römischen Religion, fasst Grotius zusammen:

„Im Allgemeinen müssen wir beide Völker für ihre Hingabe zur Frömmigkeit gegenüber den Göttern loben. Tadeln müssen wir aber ihre hartnäckige Ignoranz and generelle Vernachlässigung der Suche [nach der Wahrheit]. Wir werfen ihnen nicht ihre Ignoranz der Geheimnisse der Religion vor, die zu jener Zeit nur den Juden gegeben worden war, aber

2 Ms (geschrieben 1601-3), ist Teil eines größeren Projekts gewesen, zu dem wahrscheinlich auch De antiquitate (1610) gehörte. Der volle Titel lautet: Hugonis Grotii Batavi Parallelon rerumpublicarum de moribus ingenique populorum atheniensium, romanorum, batavorum. Das Ms. wurde herausgegeben und ins Holländische übersetzt von J. Meerman (Haarlem 1801-3). Die englische Fassung ist Teil eines Übersetzungsentwurfs von Arthur Eyffinger. 
zu kritisieren ist ihre Nachlässigkeit in der Erkenntnis, was Philosophie sie hätte lehren können. Erstens, dass der, den wir Gott nennen, das eine und auch das beste, größte und unendliche Wesen sein muss. [...] Einige hörten so schlecht auf die Lehren der Natur, dass sie es wagten, die Existenz Gottes oder seine Sorge um sterbliche Wesen zu leugnen. [...] Die Kelten, unter welchem Namen die germanischen und gallischen Völker zusammengefasst sind, [...] hatten alle den unbestrittenen Glauben, dass Gott existiert und dass Er, nicht erstarrt in festlicher Untätigkeit, sondern um das menschliche Wohlergehen besorgt, die Himmel in gleichförmiger Bewegung moderiert, und die irdische Welt durch die beständige Erneuerung der Kräfte der Natur.“3

Wir erkennen hier also eine Bevorzugung der Naturreligion sowie die Ansicht, dass die ursprüngliche Religion der Bataver in ihren Strukturen christlich war. Außerdem, schreibt Grotius, verfielen die Bataver nicht dem Götzendienst - im Gegensatz zu den Juden, die in verschiedenen Fällen Gottes Gebote brachen [280r]. Grotius stellt sogar die Hypothese auf, die Perser hätten ihre religiösen Auffassungen von den Germanen entlehnt, so wie die Ägypter den germanischen Gott Mercur als ihren übernahmen [281].

Antike und ein ,natürliches` Christentum prägen den batavischen Glauben. Aberglauben in Religion, erinnert uns Grotius, hat auch eine politische Funktion: „Wenn die Gesellschaft nur aus kenntnisreichen Personen bestünde [ex solis sapientibus], gäbe es keine Notwendigkeit für diese Fabeln. Da aber das lasterhafte und hitzige gemeine Volk leicht in Erregung oder Wut gerät, sollten seine Emotionen durch die Furcht vor himmlischen und höllischen Göttern kontrolliert werden; und deshalb war es weniger gefährlich, diese Dinge einzuführen, als wenn man sie entfernen würde.“ [278r] Polybios zufolge hatten die Römer dies verstanden und das rechtfertigte ein wenig ihre religiösen Verirrungen. Naturreligion, Christentum und die Politik der Religion stehen somit im Mittelpunkt von Grotius frühem Interesse de religione et pietate.

Nachdem er scherzhaft anmerkt, dass Mercur von seinen holländischen Landsleuten immer noch sehr verehrt wird, beginnt Grotius mit einer Erörterung der wahren Religion. Dabei handelt es sich im Wesentlichen um die Geschichte der Christianisierung der Niederlande, die zur Reformation führende Auflösung der Katholischen Kirche, die Inquisition und die Befreiung. Die Schicksalsschläge des Papsttums sind im wesentlichen: Ablässe, die unergründlichen Folgen des Zölibats, die Trübung des Wortes Gottes, die Erfindung des Fegefeuers und die damit verbundene Aneignung des Geldes, wenn nicht der Seelen, der Verstorbenen. Das Christentum lebt von Unterdrückung, und durch den Tod des Katholizismus entstand neues Leben, gutes wie schlechtes. Das Schlechte liegt im Bekenntnis der Anabaptisten und Mennoniten, demzufolge aufsässige und ungläubige Menschen zu Recht zur Ordnung gezwungen wurden; das Gute liegt hingegen in der Reformation, insbesondere im

Ebd., F.278v/279r. Dieses letzte Kapitel ist Kapitel XXVI: De religione et pietate. 
Calvinismus begründet (da sich ,unsere Nachbarn` von der Reformierten Religion ,abgewendet haben` [a qua finitimi iam desciverunt, F301v].

„Wir bezeugen, dass wir nur einen Gott anbeten sollen, dass Christus allein der Urheber der Erlösung ist, nur eine Bibel die Richterin in Streitfragen, dass die Sünde die einzige Essenz des Menschen ist. [...] Wir erzwingen nicht, sondern wir empfehlen; diejenigen, die abweichen, verdienen Mitleid, nicht Bestrafung; wir herrschen nicht über die Gedanken, wir bedrängen nicht die Seelen. Jeder glaubt das, was er kann. Auch hier muss Freiheit ungetrübt sein. Jeder Einzelne soll seiner eigenen Religion folgen, weil es Religion ist und seine; im allgemeinen und in der Öffentlichkeit sollte nur der besten Religion gefolgt werden.“

Die natürliche Religion, calvinistische Prinzipien, ein humanistisches Verständnis der öffentlichen Funktion der Religion sind gepaart mit einem stolzen und selbstbewussten Verständnis der Ursprünge, Geschichte und Leistungen des holländischen Volkes: zweifellos Toleranz und Freiheit, aber auch eine starke Überzeugung, dass die Holländer eine natürliche Neigung zu dem haben, was vernünftig und moralisch ist.

Ungefähr zur selben Zeit schrieb Grotius einen anderen Text, der ebenfalls als Handschrift tradiert worden ist: De republica emendanda, geschrieben vermutlich im Jahre 1599. Dieser Traktat handelt eher von Politik als von Religion, auch wenn darin Parallelen zwischen der jüdischen Republik des Alten Testaments und der holländischen Republik als Teil der Arguments angeführt werden. ${ }^{4}$

De republica emendanda gilt als Memorandum für seine Freunde im Leidener Kreis. Der Ton ist nüchtern, das Argument elitär. Es steht im Gegensatz zu seiner ersten Veröffentlichung in diesem Genre: De antiquitate reipublicae Batavicae (1610), ${ }^{5}$ einem strategisch-rhetorischen Dokument zur Beschreibung der politischen Praxis der Herrschaft Oldenbarneveldts, die in eine ehrwürdige historische Tradition gestellt wird. Auf historischer Grundlage trifft Grotius eine wichtige Unterscheidung zwischen einer Monarchie und einem aristokratischen System mit einem Fürsten (einem Prinzipat). Bei ersterem geht es anscheinend um uneingeschränkte Herrschaft, bei letzterem handelt es sich um eine, wie er es nennt, Ordinum aut Statuum regimen - eine Ständeregierung, die von einem Fürsten unterstützt wird. Die genaue Beschaffenheit dieser Stände würde von den in einer bestimmten Gesellschaft vorherrschen Unterschieden abhängen, da die Stände sozusagen das Organisationsprinzip einer Gesellschaft darstellen. Während der Fürst die maiestas der Republik aufrechterhält, verteidigen die ordines deren Gleichheit und Freiheit. Die Ordines bieten eine Gewähr gegen mögliche Herrschaftsfehler eines einzelnen Mannes, und der Fürst korrigiert die Unerfahrenheit der Menge. Fürsten herrschen mit Zustimmung des Volkes und innerhalb bestimmter Grenzen, selbst wenn ihre Position erblich ist. Monarchen dagegen

Grotius 1984.

Grotius 2000. 
sind legibus solutus.

Über diese Themen wird Grotius unter dem Einfluss der geschichtlichen Entwicklung und im Licht folgender theoretischer Innovation Variationen schreiben. Man könnte sagen, dass Grotius bereits als Teenager in die Debatten eintrat, die sein Leben beherrschen sollten: Religion und Politik. Vor allem finden wir hier schon die Grundprämissen vor: die reformierte Religion ist die wahre Religion, vorausgesetzt, sie geht einher mit Toleranz; die Rolle der Regierung ist es, auf souveräne und besondere Weise zu herrschen.

Wie bei diesem ehrgeizigen jungen Mann üblich, beendet Grotius den Parallelon mit einem Verweis auf ein noch zu schreibendes Buch: „Sed quid in hac caussa iure divino et gentium praecipi videatur atque permitti, alia erit dissertatio “ [Was in dieser Sache gemäß göttlichem Gesetz geboten und verboten ist, wird andernorts behandelt]. Es ist nicht sicher, dass er sich hier auf sein anderes Jugendwerk bezog, gemeinhin bekannt als De iure praedae, das von ius divinum und ius gentium handelt, wenn auch nicht von Religion, aber es ist gut möglich. ${ }^{6}$ Auf jeden Fall hat Grotius in De iure praedae, ${ }^{7}$ geschrieben $1604-5$, zum ersten Mal sein Verständnis des Naturgesetzes entwickelt. Zweifellos macht er sich auf den Weg zu einer bedeutenden Innovation in der Naturrechtstradition und wird zurecht als praeceptor iuris naturalis, Gründer des modernen Naturrechts, betrachtet. Da keine allgemeine Übereinstimmung über Grotius' Leistungen im Naturrecht besteht, merken wir - für den aktuellen Kontext - nur kurz an, dass wir den innovativen Charakter dieses Werks erkennen sollten. Und gemäß dem Thema dieses Kapitels muss dies aus der Perspektive von Religion und Politik geschehen.

De iure praedae [DIP] ist im wesentlichen ein Buch über Gerechtigkeit und Bestrafung; nicht über Religion, aber doch über Gott. Es entwickelt eine Theorie von Mensch und Gesellschaft, von Politik und Souveränität, bei der die Notwendigkeit betont wird, Gott zu kennen. Es ist ein Werk zur Politischen Theologie, auch wenn es nicht die Themen Kirche und Staat behandelt. DIP beginnt mit der Frage des gerechten Krieges und präsentiert dann ein umfassendes Bild der Beziehung zwischen Gott und seiner Schöpfung sowie zwischen einzelnen Menschen und Staaten als Werke Gottes. Interessanterweise wird jedoch in der Einführung zu DIP behauptet, dass die Argumente nicht in der Bibel oder im Römischen Gesetz gesucht werden, sondern in den Grundlagen der Philosophie (ex intima philosophia). Folglich treffen wir auf eine sehr philosophische Vorstellung von Gott, die Gottes Willen und Schöpfung nebeneinander stellt. Wir Menschen sind das Werk des Bildners und

$6 \quad$ Es ist argumentiert worden, De iure praedae sei ein Gelegenheitswerk und dass insbesondere die Kapitel über natürliches und göttliches Recht im Hinblick auf die Rechtfertigung der substantielleren Behauptungen verfasst wurden. Allein die Tatsache der Ankündigung im Parallelon lässt eine solche Interpretation jedoch fragwürdig erscheinen.

7 De iure praedae commentarius, hrsg. v. H. G. Hamaker (The Hague 1868), übersetzt als Commentary on the law of prize and booty, v. Tr. G. L. Williams (Oxford 1950). 
sollten daher seinem Befehl folgen. „Was Gott als seinen Willen offenbart hat, das ist Gesetz“, lautet die erste regula, gefolgt von der Bemerkung, dass Gott von uns verlangt, dass wir den Zweck seiner Schöpfung aus der Schöpfung selbst verstehen können. ${ }^{8}$ „Aus dieser Tatsache haben die alten Dichter und Philosophen zu Recht gefolgert, dass Liebe, deren primäre Kraft und Tat auf Eigeninteresse ausgerichtet sind (cujus prima vis primaque actio reciproca est in se ipsum), das erste Prinzip der gesamten natürlichen Ordnung ist. “ Anschließend definiert Grotius das Erste und Zweite Naturgesetz: das Recht auf Selbstverteidigung und auf Eigentum.

Gegenseitige Verpflichtungen sind schnell die Folge und rasch wird ersichtlich, dass Gerechtigkeit häufig nicht respektiert wird. Bestrafung, glaubt Grotius, hat den Zweck, Gerechtigkeit in der Welt zu fördern. Jedem Individuum könnte die Verpflichtung zukommen, Bosheit zu bestrafen und durch das Beispiel künftiges Übel zu verhindern. Offensichtlich wird in DIP Gerechtigkeit durch die bloßen Gesetze und Regeln definiert, von denen sich das Recht zu bestrafen ableitet.

Es gibt jedoch einen zweiten Sinn von Bestrafung, nämlich Gottes Bestrafung unserer Sünden, die von anderer Art ist als die menschliche Bestrafung böser Taten. Unsere Sünden sind also sozusagen wesentlicher Bestandteil unserer Natur (böse Taten als solche hingegen nicht), und Gott hat eine besondere Verantwortung für unser Wohlergehen. Daher hat Er beschlossen, unsere Sünden in Christus zu bestrafen und uns dadurch von der ewigen Bestrafung zu erlösen, die wir ansonsten verdienen würden.

Der Minimalismus von DIP hat tatsächlich weitreichende Konsequenzen. Grotius wird fortfahren, diese zu verteidigen. Eine erste Gelegenheit bietet sich als nach dem Tod des Arminius im Jahre 1609 die religiösen Spannungen zunehmen und calvinistische Extremisten Tumulte inszenieren und Arminianer angreifen. Die Regenten in den holländischen Städten ihrerseits ernennen weiterhin liberale Geistliche in ihre Kirchen - zur großen Entrüstung der calvinistischen Orthodoxie. Hugo Grotius reagiert auf diese Ereignisse mit Bestürzung. Seine persönliche Meinung, dass die tieferen Fragen der Religion für das Glaubensbekenntnis nicht wesentlich sind und es äußerst schädlich ist, wenn sie mit gewöhnlichen Kirchenleuten diskutiert werden, schlug sich nieder in dem eindrucksvollen Aufruf zu christlicher Toleranz in seinem Manuskript Meletius, das er vor oder im Jahr 1611 verfasste. Der Name geht zurück auf den byzantinischen Bischof und Patriarchen von Alexandria, Meletius Pegas (1572-1638), einem persönlichen Bekannten von Janus Dousas Sohn Joris, der den Bischof auf seinen Reisen im Nahen Osten traf. ${ }^{9}$ Melitius stand für christliche Versöhnung und gab Anstoß zu diesem irenischen Essay, Grotius’ erstem apologetischen Werk. Das Christentum mit anderen Religionen und philosophischen Ideen über Gott ver-

8 Dei voluntas non oraculis tantum et extraordinariis significationibus, sed vel maxime ex creationis intentione apparet. DIP, II, 8.

$9 \quad$ Zu Einzelheiten vgl. die Einführung in Meyjes 1988:17 ff. 
gleichend, folgert Grotius, dass das Christentum den anderen ,falschen und weniger falschen' Religionen weit überlegen ist, insbesondere da das Christentum eher die freie Frömmigkeit des Gläubigen erfordert, als die rein äußerliche Befolgung einiger Riten. Daher können die grundlegenden Glaubenssätze des Christentums wenige sein: 1. das Gott existiert, 2. das Gott belohnt. Alle anderen Dogmen sind strittig und sollten dem einzelnen Gläubigen überlassen sein. Das bedeutet allerdings nicht, dass Grotius keine eigenen festen Ansichten zu diesen weitergehenden Fragen hätte. Selbst wenn er zur Verteidigung der minimalen Definition des Christentums argumentiert, erörtert er einen Streitpunkt nach dem anderen, und stellt Behauptungen auf, die er ansonsten für indifferent halten würde. Das muss seine Leser verwirrt haben. Sicherlich verwirrte es Antonius Walaeus, mit dem er intensiv über den Meletius korrespondierte. ${ }^{10}$

Zwei grotianische Merkmale sind herausragend. Zunächst einmal sehen wir hier proprie aut stricte dictum versus largissime sumitur des De iure belli ac pacis (I, I, 5-9), eine Unterscheidung, die den Unterschied zwischen essentieller Wahrheit versus plausiblem Konsens zu bezeichnen scheint. Grotius versucht zu zeigen, dass seine beiden grundlegenden Lehrsätze des Christentums notwendig und ausreichend sind. Indem er dies rechtfertigt, rekonstruiert er, was er für den Konsens der Christen (und Nicht-Christen) hält. Vor allem der Umstand, dass seine Argumente für ein minimales Glaubensbekenntnis durch eine umfassende Erörterung christlicher und nicht-christlicher Philosophie gerechtfertigt werden, muss den Verdacht hervorgerufen haben, dass Grotius das Christentum unterminiert und es auf eine natürliche Religion reduziert. Grotius verstand die natürliche Religion als Weisheit der Philosophen ohne Offenbarung. Dieser problematische Aspekt in der Theologie von Grotius wird sich in den nachfolgenden Jahren noch verstärken.

Das zweite Merkmal könnte als Rekurs auf Hyperargumente bezeichnet werden, Argumente, mit denen versucht werden soll, der fruchtlosen Gegenüberstellung von Meinungen zu entkommen, die den zugrundeliegenden Konsens verdecken. Grotius versucht aufzuzeigen, was Christen gegenüber Nicht-Christen miteinander verbindet. Da aber unter Christen eine derartige Meinungsverschiedenheit herrscht, möchte er umso mehr beweisen, dass die Kernpunkte des Christentums wirklich universale, im Wesentlichen von allen rechtdenkenden Menschen angenommene Wahrheiten sind. Der consensus omnium wird hier den dogmatischen Spaltungen innerhalb des Christentums gegenübergestellt.

Es ist nicht klar, welche dieser beiden Strategien seine Landsleute mehr erboste. Es muss die orthodoxen Vertreter der Prädestination irritiert haben, dass Grotius der Prädestination keinen Platz im reformierten Dogmatismus zugestand, aber dann dieser Position doch das Wort erteilt, indem er behauptet, dass der Mensch frei, soziabel, mit Geist, Körper und Lei-

10 Vgl. BW, I, 214 (Walaeus an Grotius, 1 Nov 1611), 215 (Grotius an Walaeus, 11 Nov 1611), 216 (Walaeus an Grotius, 1 Dec 1611), 221 (Grotius an Walaeus, 11 Jan 1612), 232 (Walaeus an Grotius, April 1612). 
denschaften geschaffen ist; dass Christus für die Sünden aller Gläubigen starb; dass das ewige Leben jedem Christen versprochen worden ist. In seinen Kommentaren zum Alten und Neuen Testament wird Grotius diesen Ansatz zum Christentum weiterführen. Es ist eine starke Verteidigung des Christentums, die auf dessen Universalität und Fähigkeit baut, Teilwahrheiten innerhalb anderer Traditionen aufzugreifen und einzubeziehen. Aber es besteht immer die Gefahr, dass, um diese Universalität zu erreichen, die Dogmen abgeschwächt und verallgemeinert und aus den warmen Gefühlen der Gemeinschaft der Gläubigen herausgezogen werden müssen, in der Dogmatismus normalerweise zu gedeihen scheint.

Im Meletius erörtert Grotius wiederholt die Beziehungen des Christentums zum Epikurismus, Stoizismus, zu Plato, Cicero und, in seiner Betonung des freien Willens (prohairesis) und menschlichen Teleologie, zu Aristoteles.

Harm-Jan von Dam zufolge war Grotius nicht davon überzeugt, dass Meletius einen starken Einfluss auf die zunehmenden religiösen Spannungen innerhalb der holländischen Gesellschaft haben würde. Bei der Arbeit an einem neuen Projekt - Ordinum pietas, das schließlich 1613 veröffentlicht wurde -, ging er daher sehr viel kühner vor und wendete sein gesamtes rhetorisches Geschick und Wissen zur Erreichung seines Ziels an.

Er wurde zu der Aufgabe berufen durch ,große Männer, durch die Notwendigkeit der Arbeit, durch die Gefahr für die Republik“, wie er an Daniel Heinsius schrieb. ${ }^{11}$

Ordinum pietas (1613) [OP] wurde in höchstens einem Monat geschrieben und enthielt Material, das er bereits für Meletius zusammengetragen hatte, nun aber zu einem anderen Zweck verwendete. OP war ad hominem und gegen Sybrandus Lubbertus gerichtet. Dessen Angriff auf Conradus Vorstius und die Holländischen Staaten hatte einen heftigen Streit um die Berufung dieses Professors aus Steinfurt auf den Lehrstuhl für Theologie in Leiden ausgelöst, der nach dem Tod von Jacobus Arminius (1560-1609) vakant war. Vorstius war des Sozinianismus beschuldigt worden, zum Teil infolge eines Scherzes von Studenten, die ein anti-sozinianisches Traktat von Vorstius fälschten, um ihren Lehrer Lubbertus zu erzürnen. Auf der Grundlage einer umfassenden Bearbeitung patristischer Schriften, insbesondere solcher der frühen Christen, die an der Entdeckung der Verbindung zwischen der neuen Religion und der philosophischen Tradition beteiligt waren, stellte Grotius dar, dass bereits die frühen Christen eine minimalistische Vorstellung des Christentums aufgriffen, womit sie den sogenannten Fünf Artikeln der Remonstranz vorangingen und vorwegnahmen. $^{12}$

BW, I, 297 (31. Okt. 1613).

Diese fünf Artikel behaupten im Wesentlichen, dass Gottes Gnade für alle Gläubigen Geltung hat und dass Christius für alle und jeden Menschen starb. Dem entgegen steht die These der Prädestinaten, die 
Er erzürnte die calvinistischen Extremisten mit seiner gelehrten Arroganz; er zitierte reichlich aus den Werken griechischer, hebräischer und lateinischer Autoren und argumentierte, dass es nicht notwendigerweise der Fall ist, dass Priester oder Theologieprofessoren in der Theologie versierter sind als politische Führer. Unter Verwendung des Religionsansatzes von Bodin - und Grotius ist tatsächlich bis ca. 1640 ein politique geblieben - argumentierte er, dass die letzte Autorität in der öffentlichen Kirche der Magistrat ist. Hier kommt, wie schon im Parallelon, die Unterscheidung zwischen privatem Glauben und öffentlicher Religion wieder zum Vorschein. Sie ist eine starke Unterstützung für die Sache der öffentlichen Autorität der souveränen Macht.

An einer Stelle macht Grotius die rhetorische Bemerkung, dass, sollte Lubbertus die Häresie bekämpfen wollen, man doch die Anabaptisten aus seiner Heimat Friesland vertreiben sollte. „[P]lena est Frisia anabaptistis [...] Hos Frisia si potes expelle“. ${ }^{13}$ Außerdem gibt es in OP zahlreiche Bemerkungen wie „aut imperiti aut malevoli est ... “ [entweder dumm oder böswillig], und es überrascht nicht, dass Lubbertus und seine Freunde sich hart angegriffen und schlecht behandelt fühlten. Johannes Bogerman, der 1618-9 der Synode von Dordtrecht vorstehen wird, reagierte im darauffolgenden Jahr, wie auch Lubbertus. Letzterem entgegnete Grotius in seiner Bona fides Sibrandi Lubberti (1614), die kein wirklicher Beitrag zur gegenseitigen Verständigung war. Wie Grotius und seine Freunde schnell feststellen, war Grotius durch die Veröffentlichung von OP endgültig zum Erzfeind der Calvinisten avanciert.

In dieser Situation erwägt Grotius, zwei weitere Werke zu schreiben, die sein Ansehen in der orthodoxen Gemeinschaft verbessern sollen. Dabei handelt es sich um De satisfactione Christi contra Faustum Socinum (1617), und um die später De imperio summarum potestarum circa sacra (1647) genannte Schrift. ${ }^{14}$

Obschon sehr viel vorsichtiger verfasst als OP, konnten die beiden Bücher den angerichteten Schaden nicht wiedergutmachen. Grotius wird sich schließlich von dem verloren gegangenen Respekt nie wieder erholen. Als er 1634 hoffte, wieder in seinem Heimatland Holland akzeptiert zu sein, hatte er noch immer darunter zu leiden, und nicht einmal seine persönliche Bekanntschaft mit dem Statthalter Prinz Friedrich Heinrich konnte ihm dabei helfen.

Die beiden Bücher waren sehr vorsichtig verfasst; er konsultierte andere Gelehrte im Inund Ausland und trug Wissen aus allen möglichen Gebieten zur Unterstützung seiner Thesen zusammen. In enger Zusammenarbeit mit Gerhard Vossius untersuchte Grotius zwei

annehmen, dass nach Gottes ewigem Ratschluss einige zur Gnade, andere zur Verdammnis vorbestimmt sind. Vgl. Brink 1960: 290 ff.

OP, § 31 .

Vgl. Grotius 2001. 
getrennte, sich aus dem früheren OP ergebende Fragen. Zum einen legte er die Autorität der obersten Staatsgewalt über die Kirche und die Verwaltung des Glaubens dar. Damit setzt er frühere Argumente fort, insbesondere die von Johannes Uyttenbogaert, des Geistlichen von Prinz Moritz, in seinem Werk The office and authority of the Christian sovereign power in church affairs von $1610 .^{15}$

Der generelle Stoßrichtung dieser politischen Position in Angelegenheiten von Kirche und Staat lässt sich leicht zusammenfassen. Die oberste Gewalt in einer Gesellschaft ist notwendigerweise eine einzige, und zwar die höchste und die autoritative. Das bedeutet, dass alle Untertanen, einschließlich der Kirchenmitglieder, zu gehorchen haben. Die oberste Gewalt sollte ferner alle Fragen von öffentlichem Interesse festlegen, selbst wenn dies durch Delegation oder Substitution geschieht. Ein Herrscher braucht die Unterstützung von Stellvertretern und Helfern, aber daraus lässt sich keine Unabhängigkeit dieser Stellvertreter oder Helfer ableiten. Souveränität bleibt ungeteilt; einen Souverän zu unterstützen impliziert nicht das Erlangen von Souveränität. Der bloße Gedanke, dass die Kirche dem Souverän befehlen könnte oder dass die Kirche unabhängig geführt wird, ist ein Widerspruch. Selbst wenn der Herrscher es nicht möchte, muss er den Anforderungen eines christlichen Herrschers und einer christlichen Kirchenordnung nachkommen. Er sollte Ratschläge annehmen, aber seine eigene Entscheidung vorbereiten. Detailliert hat Grotius nun seine Vorstellungen der richtigen Verwaltung der Kirche entwickelt. Obwohl in alten Zeiten die Herrscher Staat und Kirche zusammen regiert hatten, erfolgte in späteren Zeitaltern eine Trennung oder vielmehr Delegierung der praktischen Herrschaft der Kirche durch den politischen Herrscher. Wenn der Herrscher nicht tatsächlich über Kirchenangelegenheiten entscheidet, so herrscht er doch noch durch Ausnahmeregelung. Das ist die Situation in den Niederlanden, wo die politischen Autoritäten nur intervenieren, wenn bestimmte Themen vor die Synode gebracht oder neue Geistliche bestätigt werden müssen.

Grotius schickte das Manuskript von De imperio an den englischen Hof und nach Lingelsheim in Heidelberg. Er wartete immer noch auf Antworten aus England, als er am 29. August 1618 verhaftet wurde. Das Buch über Christi Erlösung wurde jedoch vor seiner Verhaftung veröffentlicht, obwohl sich auch hier die Beratung über mehrere Jahre hinzog. Dieses Buch, De satisfactione, spielte auf die frühere Kontroverse um Vorstius an und befasste sich mit der Korrektur Sozinianischer Irrtümer bezüglich der Art, in der wir die Vermittlung Christi bei unserer Erlösung verstehen sollten. Da Sozini die göttliche Natur Christi mit dem Argument leugnet, dass es eine Inkonsistenz wäre, Christus sowohl als Menschen als auch als Gott zu betrachten, musste die Erlösung neu interpretiert werden.

Sozini behauptet, das Leiden Christi als solches sei nicht die Ursache für die Erlösung des Menschen, sondern ein unabhängiger Akt Gottes, der den Menschen von der Bestrafung

$15 \quad$ Vgl. Uytenbogaert 1610. 
der Sünde befreit. Grotius widerspricht dieser Vorstellung, indem er behauptet, Gott wolle nicht, dass unsere Sünden ungestraft bleiben. Anschließend untersucht er den Begriff Bestrafung - dem Beispiel von DIP folgend - und reinterpretiert Christi Tod am Kreuz als eine wirkliche Bestrafung für unsere Sünden, von denen wir durch diese Bestrafung befreit worden sind. Nur ungefähr ein Jahr nach der Veröffentlichung von OP geschrieben, erstaunt es, dass Grotius die Ursachen der Gnade - Erlösung und ihre Bedeutung - erörtert, ohne sich auf die Kernfragen der Diskussion über Prädestination zu beziehen. In OP hatte er angegeben, dass er die strikte Interpretation der Prädestination der Orthodoxen für Blasphemie hielt, da sie Gott zum Verursacher des Bösen machte. Es ist jedoch nicht schwierig zu erraten, welche Schlussfolgerungen Grotius gezogen hätte. Die Verwendung einer Theorie der Bestrafung auf die theologische Fragestellung der Erlösung erstaunte einige und machte andere misstrauisch. Letztlich brachte es Grotius keinen Nutzen, da der Verdacht des Sozinianismus sich nur vertiefte, nach dem wohlbekannten Prinzip qui s'excuse, s'accuse (wer sich entschuldigt, klagt sich an). Es half ihm weder bei seiner Verteidigung gegen die Anklage wegen Majestätsbeleidigung, noch konnte es seine Verurteilung zu lebenslanger Haft in der Festung Loevestein verhindern. In dieser Festung wird er jedoch seiner politischen Theologie neue Dimensionen hinzufügen: die humanistische, wortgetreue Studie des Neuen Testaments und eine ausführliche Apologie der christlichen Religion, die später überall in der gelehrten Welt als De veritate religionis Christianae (1627) berühmt werden wird.

In der Festung wird Grotius auch seine Apologetica, oder Verantwoording verfassen, die beide 1622 veröffentlicht werden. Dabei handelt es sich um eine ausführliche juristische Darlegung der Souveränität der Staaten von Holland und des daraus folgenden Rechts für Grotius als Bürger Hollands dort und nicht vor dem von den Generalstaaten eingesetzten Gericht zu stehen. Hier sehen wir, wie Grotius von seiner ursprünglichen Pro-Union Position in De republica emendanda zu einem partikularistischen Hollandismus wechselt, der nicht recht zu seinem Supra-Nationalismus passt. Wie erinnerlich, hatten sich Grotius und seine politischen Freunde für eine Generalsynode aller Reformierten Kirchen ausgesprochen, um eine günstige Meinung in der Frage der Prädestination zu erzielen. So weit ich sehen kann, wird Grotius nach 1618 das Thema politische Theologie nicht mehr systematisch aufgreifen. Seine zunehmende Irritation über den holländischen Calvinismus und Protestantismus im Allgemeinen ist spürbar. Die Sekundärliteratur greift diese Entwicklung mit dem Verdacht eines Grotianischen Papismus' in gewissen Kreisen auf. Das sollte uns hier nicht weiter beschäftigen. Wir sollten nicht versuchen, die Frage zu beantworten: Was hoffte Grotius mit seinem Veröffentlichungsprogramm zu erreichen?

\section{Hatte Grotius eine intellektuelle Strategie?}

In Grotius frühen Jahren war das Publikationsprogramm sehr intensiv. Er veröffentlichte 
nicht nur eine wichtige Reihe bedeutender Werke, er hielt auch mehrere Manuskripte von der Veröffentlichung zurück. Das Projekt, welches sich Grotius selbst auferlegt hat, - Toleranz in der vorherrschenden Kirche einzuführen - wird hier behandelt. Wir haben gute Gründe nach einer Erklärung für den relativen Misserfolg zu fragen, selbst angesichts der vorherrschenden Tendenz, Grotius als einen der Architekten der modernen Toleranz zu betrachten.

Jonathan Israel beschreibt die Natur religiöser Konflikte in der frühen holländischen Republik mit den folgenden Worten:

„In Holland und Utrecht entstanden zwischen 1570 und 1580 zwei rivalisierende Traditionen [...] der orthodoxe calvinistische Flügel [...] Verfechter der Intoleranz [...] ,Libertine‘ Regenten dagegen wünschten nicht nur die Macht der Kirche zu beschränken [...] und [...] tolerantere Politik [...], sondern wollten, dass sie theologisch flexibel ist [...].

Auf diese Weise entstanden im städtischen und ländlichen Leben und in der Politik Hollands ,Partei-Fraktionen“, die aus Patronage-Netzwerken und Familieneinfluss bestanden, was ihnen (zum Teil) das Merkmal von Klientel-Systemen verlieh, die einerseits um Einfluss und Ämter konkurrierten und andererseits ideologische und theologische Strömungen, gegensätzliche Einstellungen zu Religion, Erziehung, Kultur und Lebensweise repräsentierten. Die Kopplung von Fraktions- und Klientel-Merkmalen mit politischer Ideologie und Theologie sollte sich als eines der andauernden, fundamentalen Kennzeichen nicht nur des Goldenen Zeitalters, sondern der gesamten Geschichte der Republik erweisen. ${ }^{16}$

Aus dieser Perspektive müssen wir die Frage nach Grotius’ Verbindung zu dieser Entwicklung stellen, nach seiner intellektuellen Beteiligung und seinem Verständnis für diesen Prozess und daher letztlich nach seiner intellektuellen Strategie.

Wie nahm Grotius den von Israel beschriebenen Prozess wahr? Wie reagierte er auf das, was er sah? Einfache Antworten auf diese Fragen gibt es nicht. Einer der Gründe dafür ist, dass Grotius selbst Teil des Prozesses der ideologischen Formierung des von Israel beschriebenen Parteifraktionssystems war. Vor allem von Beginn seiner Haft an, beschreibt Grotius in eindringlichen Worten den schicksalhaften Kampf zwischen den kerkelijke [wörtlich: Kirchenmännern] und den politieken [politischen Männern], d. h. zwischen der orthodoxen Oranier-Fraktion auf der einen Seite und der freisinnigen Regenten-Fraktion auf der anderen. ${ }^{17}$ In dieser Ideologie wird die holländische Republik durch gemeinsame

Israel 1995: 391/392.

Siehe z. B. Grotius 1871: 1-180. Hier beschreibt er sein Vertrauen in die fürstliche Regierung und eine Furcht vor politischer Veränderung, insbesondere wenn sie durch Unruhe im Volk hervorgerufen wird (ebd.: 11/12): “Alle welcke dingen mij achterdencken gaven, off datter waren dye Sijn Ex ${ }^{\text {tie }}$ rieden den tijdt waer te nemen om de oude pretensiën uyt te voeren, ofte immers om nae 't exempel van Philippus van Macedoniën, (dye onder 't pretext | van de Religie voor te staen 't eene deel van Griekenlant door het andere vermeesterde) ende van Augustus te Rome, dye beyde haer te vrede hadden gehouden met den naem van Capiteyn-Generael, den schijn latende van de oude Regiering, de kracht aen haer te tre- 
Aktionen politisch eifernder Geistlicher, ihrer leichtgläubigen Anhängerschaft und monarchisch ambitionierter oranischer Fürsten an den Rand des Zusammenbruchs gebracht. Gegen diese Angriffe stellen nur die nüchtern denkenden Regenten eine vertrauenswürdige Verteidigung dar, wenn sie nur auf die rechte Vernunft und nicht auf die Stimmen des intoleranten Fundamentalismus hören würden. Nach 1618 geht es für Grotius, wie auch für die späteren Staatspartei-Ideologen, in der strittigen Frage um die aristokratische Regierung, die rechte Vernunft und folglich um die gute Bildung im Gegensatz zum wankelmütigen Enthusiasmus der Auserwählten Gottes. Für die vor 1618 verfassten Schriften ist es jedoch schwierig zu entscheiden. Es fehlen in erster Linie anti-oranische Anspielungen oder eine starke Präferenz für die fürstlich aristokratische Republik wie in der frühen De republica emendanda. Ähnlich beschränkt sich Grotius’ Unduldsamkeit gegenüber ungebildeten Mitbürgern nicht auf den Pöbel, sondern umfasst auch die rustici unter den Regenten. ${ }^{18}$ Selbst im Bereich von Religion und Theologie wird nicht deutlich erkennbar, dass Grotius seine eigene spätere Analyse vorwegnahm, wie unsere Erörterung der Ordinum pietas zeigte.

Was dachte Grotius also, was er im Begriff war zu tun? An einer Stelle lässt er uns nicht im Unklaren. Im Meletius sagt er, „Es war sowohl meine Absicht, Christen anzuregen, einander dafür zu lieben, was sie gemeinsam haben als auch die anderen dazu zu bewegen, ebenfalls die gemeinsame christliche Konfession anzunehmen“. ${ }^{19} \mathrm{Zu}$ dieser Intention einer Einigung und Bekehrung fügt sich das Widerstreben von Grotius, die Meinungsverschiedenheiten unter den Christen zu betonen, schon deswegen, weil ihre Unterschiede schwerwiegend sind.

Die große und vehemente Rechtfertigung der Staaten von Holland in der Ordinum pietas war offensichtlich dazu bestimmt, die Anhänger der Prädestinationslehre davon zu überzeugen, dass die Staaten aus guten Gründen die Lehre dunkler und schwieriger Dogmen verurteilt hatten, wo einfache und unkomplizierte Wahrheiten ansonsten ausreichen. Hier, wie im Meletius, wollte Grotius anscheinend überzeugen und korrigieren. Er war noch nicht in der von Israel beschriebenen Identitätspolitik involviert, die den dramatischen Ereignissen von 1618/19 folgten. Wenn etwas falsch war an Ordinum pietas, dann ihre unverhohlene Arroganz und der Anspruch auf intellektuelle Überlegenheit. Es war ein gefährli-

cken; gelijck oock te Florence in 't eerste was geschiet bij dye van Medicis, aannemende de defensie van de Gemeente jegens de Regierders. Wat mij aengaet, ick heb gemeent dat de Aristocratique Regieringe met soo veel goeds en bloeds zijnde vercregen en van Godt soo merckelick gesegent, niet en diende verandert in de Monarchie, die schoon voor het eerste wel zijnde bedient, daernae soude mogen vervallen in arger handen, gelijck tot Rome en op meer andere plaetsen in gezyen. Dan hoewel alle veranderingen mij quaedt dochten (sulcx oock, dat ick altijdt den Advocaet van 't Lant heb ontraden deze saeck te leggen in deliberatie) so docht mij vooral quaedt te zijn een verandering, dye door populaire commotie te wege gebracht soude werden.” Die Argumentation des Memorie war Teil von Grotius’ Verteidigung vor dem Gericht der Generalstaaten im Jahre 1619.

18 De republica emendanda.

19 Zitiert und übersetzt von Posthumus Meyjes 1988: 25, aus BW, I, 221 (Grotius an A. Walaeus, 11. Jan. 1612). 
cher Text, wie Grotius bald feststellen sollte.

Grotius war von den Reaktionen auf Ordinum pietas sehr überrascht und wollte den Eindruck, den er hinterlassen hatte korrigieren. Wie wir gesehen haben, wurden die beiden zu diesem Zweck verfassten Bücher De imperio summarum potestatum circa sacra und De satisfactione Christi fast direkt nach Ordinum pietas geschrieben. Bei der Niederschrift und Edition setzte Grotius seinen ganzen Intellekt und diesmal auch seine ganze Selbstbeherrschung ein. Grotius schickte die Manuskripte an Freunde (immer an G. J. Vossius, manchmal an G. M. Lingelsheim, auch an solche aus dem anderen Lager wie D. Heinsius oder F. Hommius), um die Rezeption zu prüfen, wenn er auch seine Gedanken und Darstellung deswegen keineswegs schnell änderte.

In beiden Werken sollte daher das Beste zu finden sein, das er zu bieten hatte in dem neuen Bestreben, diejenigen zu überzeugen und zu bekehren, die er durch den Einfluss einiger Eiferer in die Irre geführt glaubte. Zumindest scheint klar zu sein, dass Grotius nicht im Geringsten bewusst war, dass sein Kampf mühselig und zum Scheitern verurteilt war. Was versuchte Grotius also, seinen Gegnern aufzuzwingen? Wie wir gesehen haben, sind diese beiden Gegenmaßnahmen zu Ordinum pietas darauf ausgerichtet, zwei einfache Wahrheiten darzulegen:

1. Es ergibt sich aus der Natur der menschlichen Gesellschaft, dass es nur eine höchste Gewalt geben kann, der folglich gehorcht werden sollte.

2. Gott will jeden vor der Verdammnis retten.

Wie wir gesehen haben, erörtert Grotius diese beiden Lehrsätze mittels einer wohlüberlegten Präsentation verfügbaren Gelehrtenwissens, vor allem unterstützt von Konzepten und Argumenten aus seiner Schrift De iure praedae.

Wenn dies Grotius’ Strategie bei der Verfassung seiner bedeutendsten Schriften vor 1618 war, können wir sicher annehmen, dass das Ergebnis ihn überraschen musste. Noch im Memorie von 1619 erklärt er seine Absicht aufzuzeigen, „dass die obersten Gewalten die Pflicht haben, Gottes Wort zu suchen, so dass sie nichts dagegen anordnen können und folglich das Recht haben, mit gutem Gewissen die öffentliche Kirche und den öffentlichen Gottesdienst zu regeln, ohne jedoch diejenigen zu verfolgen, die vom rechten Urteil abweichen. ${ }^{20}$ Grotius glaubte, dass eine vernünftige Regierung in der Lage wäre, Kirchenangelegenheiten auf aufgeschlossene und verantwortliche Weise zu leiten, schon allein deswegen, weil sie nicht von rebellischen Geistlichen oder respektlosen Kirchenmännern gestört wird.

Das Argument gegen eine Nebenständigkeit der Kirche (Kollateralismus) von Johannes Uyttenbogaert hatte ursprünglich einen schwerwiegenden Mangel, denn es erklärte nicht,

$20 \quad$ Vgl. Grotius 1871: 6 . 
wie sich die Kirche zu Gott verhält, wenn sie der obersten Gewalt des Staates untertan ist. ${ }^{21}$ Da es nur eine souveräne Autorität gibt, wie Grotius in De imperio behauptet, liegt die Herrschaft über die Kirche folglich bei der höchsten Gewalt, selbst wenn sie diese Funktion an die Geistlichen und anderen kirchlichen Würdenträgern delegiert. Da dies durch Delegation geschieht, besteht keine Möglichkeit, Widerstand gegen den von Gott Gesalbten zu rechtfertigen.

In Kombination könnte diese Position, von einem intellektuellen Standpunkt aus betrachtet, beeindruckend wirken. Sie bestreitet Hotmans Ansicht in Vindiciae tyrannis, der behauptet hat, dass es einen dreifachen Vertrag zwischen Gott, Volk und Herrschern gäbe. ${ }^{22}$ In Verbindung mit der Pflicht, religiöse Abweichung zu tolerieren, könnte Grotius’ Ansicht sogar Bewunderung hervorrufen, aber sicherlich nicht bei den Auserwählten Gottes, die an eine essentielle Unterscheidung zwischen den Erwählten und den Verdammten glaubten. Im dritten Kapitel von De imperio legt Grotius diese Unterscheidung ausführlich dar, indem er den Unterschied zwischen äußeren Handlungen und inneren Handlungen aufzeigt, d. h. Gewissen und Überzeugungen, wobei für äußerliche Handlungen der Gerichtszwang als zulässiger Gegenstand angezeigt wird. Dieses schwerwiegende Argument von Grotius muss den Anhängern der Prädestinationslehre beleidigend und grausam erschienen sein, da für sie die Wahrheit unter den Gerechten, den zum Heil Prädestinierten, gefunden werden muss.

Jüngste Untersuchungen der Calvinistischen Reformation haben die Disziplinierungspolitik hervorgehoben, welche die tatsächliche Praxis des religiösen Lebens durchdrang. Diese Untersuchungen folgen der Studie von Gerhard Oestereich (Niederländische Bewegung): die Entwicklung der holländischen politischen Kultur von Lipsius’ neostoischer politischen Philosophie hin zum modernen bürokratischen Staat durch einen Prozess disziplinarischer Kontrolle. ${ }^{23}$ Die protestantischen Kirchen, so wird argumentiert, haben massiv zu diesen Entwicklungen beigetragen, da die Kirchenräte sehr tatkräftig waren, ihren Gläubigen Regeln für ein ehrbares Leben aufzuerlegen. In einem anderen Zusammenhang werde ich argumentieren, dass diese Disziplinierungsthese mit Vorsicht verwendet werden sollte und leicht irreführen kann. Sicherlich war es Absicht und Ziel der Kirchenräte, den moralischen

21 Vgl. Uytenbogaert 1610. Der Ausdruck kollateral war insofern Teil der politischen Geschichte der Niederlande als Karl V. im Jahre 1531 die sogenannten Collaterale Raden (Kollateralen Räte) an seinem Hof in Brüssel eingeführt hatte. Da Karl den Adel beschwichtigen musste, dessen Rolle gegenüber den Beamten eingeschränkt wurde, suggerierte der Begriff eine Gleichrangigkeit dieser drei Räte (Geheimrat, Finanzrat, Staatsrat). Uyttenbogaert argumentierte, collateraliteit würde zu einer Ungenauigkeit hinsichtlich der Position der souveränen Macht führen. Außerdem behauptete Uyttenbogaert, dass es nur zwei praktizierbare Modelle gibt: das der Papisten, wo der Papst über den weltlichen Autoritäten steht, oder das der holländischen Regenten, wo die Herrscher über der Kirche stehen.

22 Grotius lehnt die Monarchomachen explizit hauptsächlich aufgrund dieser Inkonsistenz ab: De imperio, III,6; III,8.

23 Vgl. hier Breuer 1986: 45-69 und Lottes 1992. 
Lebensweg ihrer Glaubensbrüder zu kontrollieren, schon deswegen, weil die durch Gottes ewigen Ratschluss Geretteten ein leuchtendes Beispiel Seiner Weisheit sein sollen. Die wirkliche Frage ist jedoch, ob es ihnen gelang? Hier ist die Sache komplizierter. In zumindest einem Fall könnten wir folgern, dass es dabei vielleicht eher um die Absicht oder den Wunsch ging als um die tatsächliche Praxis. Catterells Studie ist ein schönes Beispiel für eine Diskussion des Unterschieds zwischen offiziellen Erwartungen und tatsächlicher Realität. ${ }^{24}$ Catterell beschreibt die Bemühungen der schottischen Calvinisten in Rotterdam, die in der ersten Hälfte des 17. Jahrhunderts ihre disziplinarische Kontrolle über ihre Glaubensbrüder (natürlich auch ihrer Schwestern) hinsichtlich der Einhaltung der Zehn Gebote und des öffentlichen Anstands aufrechterhalten wollten. Als Einwanderer hatten sie Imagepflege zu betreiben und wollten verhindern, dass ein fauler Apfel den ganzen Korb verdirbt. Wie dem auch sei, es stellt sich jedoch überraschenderweise heraus, dass dieses Ziel zunehmend von der leichter verfügbaren öffentlichen Lösung der Prozessführung konterkarriert wurde: nämlich mit Hilfe von Notaren und Advokaten sowie anderer öffentlicher Persönlichkeiten potentielle und tatsächliche Konflikte auszuräumen und das Aufkommen sozialer Zerrüttung zu verhindern. Die Schotten hatten offensichtlich erwartet, in Rotterdam eine calvinistische Praxis vorzufinden, die faktisch nicht vorhanden war. Die sich daraus ergebende Angst vor einem moralischen Verfall ist leicht vorstellbar. Und wir finden tatsächlich genügend Verweise auf die Gefahren moralischer Laxheit innerhalb der Kirchen. Wenn die Holländer Gottes Gnade aufgäben, werde die gegenwärtige erfolgreiche Entwicklung des Krieges zwangsläufig zu einem Stillstand kommen und alles könnte verloren gehen, was unter großem Opfer gewonnen worden war. Der Wunsch nach religiöser Orthodoxie, pflege ich zu argumentieren, ist doppelt präsent, weil er bereits auf im Rückzug begriffen ist. Die Calvinisten sind über die moralische Laxheit und theologische Gleichgültigkeit der Arminianer aufgebracht, vor allem da diese Orthodoxen in erster Linie auf der Verliererseite waren. Hauptsächlich von südholländischer Herkunft, sahen diese neuen strebsamen Bürger des wohlhabenden Hollands, wie ihre reichen Mitimmigranten die religiöse Strenge des wahren Calvinismus aufgaben, so wie sie auch Zeugen ihres wachsenden Wohlstands und ihrer sozialen Integration wurden. Orthodoxie und disziplinarischer Eifer wurden daher zu einer letzten Stütze im unvermeidlichen Niedergang. Obschon sie die Existenz unterschiedlicher Sekten akzeptierten (Anabaptisten, Lutheraner, sogar Katholiken (aber keine Sozinianer), verhielten sie sich unnachgiebig als sie feststellten, dass ein Sektierertum auch in Gottes eigener Kirche Eingang gefunden hatte. Die Orthodoxen betonten nun stärker als zuvor, dass vor allem die Einheit der Kirchen aufrecht zu erhalten war.

Grotius Beschäftigung mit den sogenannten Kirchenunruhen im Zwölfjährigen Waffenstillstand (1609-1621) ist in diesem Kontext zu verstehen. Grotius veröffentlichte in diesen Jahren zwei bedeutende Texte über das Verhältnis von Kirche und Staat: Ordinum Pietas 
von 1613 und De satisfactione Christi von 1617. Außerdem beendete er 1617 die Arbeit zu seiner 1647 veröffentlichen De imperio summarum potestatum circa sacra. In der späteren Historiographie des Konflikts zwischen Arminianern und Gomaristen - oder Remonstranten und Gegen-Remonstranten, d. h. zwischen Liberalen und orthodoxen Calvinisten - ist es üblich geworden, diese Episode als regelrechten Bürgerkrieg und gesellschaftsumfassenden Konflikt zu betrachten, der keine Optionen für Neutralität ließ. Wir müssen uns bewusst sein, dass dieses Bild im Rückblick geschaffen worden ist. Ab den 1640er Jahren haben bedeutende Historiker beider Seiten die jeweils andere Seite in düsteren Farben und mit spitzer Feder beschrieben. ${ }^{25}$

Aber in den Jahren bis zur endgültigen Zuspitzung des Konflikts im Jahre 1618, durch den Staatsstreich von Statthalter Prinz Moritz, waren beide Seiten überrascht, dass die alten Mechanismen der Akkommodation nicht mehr funktionierten. Traditionellerweise kooperierten Staat und Kirche, wenn es auf der Ebene der einzelnen Kirche zu Streit kam. Geriet ein Geistlicher in offenen Streit mit einem Kollegen oder dem Konsistorium (die meisten Kirchen hatten mindestens zwei Geistliche die dem Kirchenkonsistorium verantwortlich waren), wurde ein ganzes Verfahren in Gang gesetzt, an dem andere Kirchen, Geistliche, Vertreter der Zivilbehörden (Stadt, Staaten) beteiligt waren. Auf diese Weise wurden die Konflikte mit Dirck Coornhert in den 1670er und 1680er Jahren sowie auch mit anderen heterodoxen Geistlichen geregelt. ${ }^{26}$ Die Wiederherstellung der Einheit war eine einigende Kraft innerhalb der reformierten oder calvinistischen Kirchen. Auf ähnliche Art hofften die holländischen Staaten den Streit zwischen Arminius und Gomarus über die Frage der Prädestination ausräumen zu können: durch Konferenzen, Beratungskomitees und politische Intervention. Gleichzeitig gab es in holländischen Städten eine spürbare Tendenz, die Benennung moderater Geistlicher zu bevorzugen.

Wir haben es also mit zwei gegensätzlichen Entwicklungen zu tun: vor 1618, als die Haltung der Gegen-Remonstranten noch unbeugsam, hartnäckig und radikal war, ist Grotius zuversichtlich gewesen, dass die politische Seite gewinnen könnte. Nach 1618, als die Gegen-Remonstraten zu gesetzestreuen Bürgern und Mitgliedern einer privilegierten, aber in keiner Weise allmächtigen Kirche geworden waren, hielt Grotius die holländische Gesellschaft für geteilt durch einen existentiellen Gegensatz zwischen den Kräften der Dunkelheit und denen des Lichts. ${ }^{27}$ Offensichtlich bedeutete für Grotius sein eigener Fehlschlag, einer unwilligen calvinistischen Kirche seinen Toleranzbegriff aufzuzwingen, dass überhaupt keine Toleranz erreicht wurde. Dabei übersah er den bedeutenden Grad von Toleranz, der als einfache Folge aus dem Konflikt zwischen Remonstranten und Gegen-Remonstranten

\footnotetext{
25 Uytenbogaert, Trigland und Brandt waren die Hauptbeteiligten an dieser Rekonstruktion; vgl. Uytenbogaert 1646, Trigland 1650 u. Brandt 1663.

Siehe nun in Übersetzung Bonger 2004.

Vgl. auch Blom 1996: 145-154.
} 
entstand. Er übersah das Ausmaß, in dem holländische Toleranz in diesen entscheidenden Jahren Gestalt angenommen hatte.

Hugo Grotius war der Befürworter irenischer, toleranter Einstellungen in Kombination mit einer starken, aristokratischen Regierung. Er hatte Anteil am Prozess hin zu einer Gesellschaft, in der unverblühmt die religiösen Unterschiede in einem ausbalancierten politischen System toleriert wurden.

\section{Grotius’ Politische Theologie}

Bis zu seiner Verhaftung im Jahre 1618 hatte Grotius vier namhafte Werke publiziert: $M a$ re liberum (1609), De antiquitate (1610), Ordinum pietas (1613) and De satisfactione (1617). Außerdem war er Autor mehrerer politischer Texte über die Staaten, mit denen er die politischen Ziele Oldenbarneveldts unterstützen wollte. Das Paralellon, der Meletius und De iure praedae waren noch nicht erschienen, ebensowenig wie Ordinum pietas. Daher blieb Grotius vor seinem Exil der allgemeinen Öffentlichkeit teilweise verborgen. Vom Meletius wissen wir zumindest, dass er das Werk verbreitete und erörterte, auch mit Gelehrten, die seine Position nicht unterstützen würden, wie Antonius Waleaeus. Hinsichtlich der Leserschaft von De iure praedae sind wir im Unklaren. So gibt es im Jahre 1618 eigentlich zwei politische Denker: den öffentlichen Grotius und den Grotius absconditus. Ersterer bemühte sich um Vorsicht und war auf das Erreichbare bedacht. Letzterer war radikaler, nur um dann wieder hinter der neuen Vorsicht des De iure belli ac pacis und den Annotationes zu verschwinden.

Einige Historiker kümmern sich nicht um diese Fragen und treten mit einer kühnen Interpretation von Grotius vor. Für diese Thematik geht der vorherrschende Trend dahin, Grotius von Beginn an als den Erz-Republikaner und Erz-Arminianer zu betrachten, der er nach Ansicht älterer Generationen im 17. Jahrhunderten gewesen sei. Demzufolge hat er eine pragmatische Religionspolitik formuliert, aufgebaut auf Toleranz und der Vorherrschaft der politischen Behörden über die öffentliche Kirche, die mit einem gleichermaßen irenischen internationalen Recht und Bibelstudium einhergeht.

Andere, insbesondere Richard Tuck, halten dies für eine falsche Sichtweise. Sie meinen, dass die drastische und innovative Sozialtheorie in De iure praedae wesentlich für das Verständnis von Grotius ist und uns veranlassen sollte, seine spätere Publikationstätigkeit als eine Abweichung - oder ist es: Verschleierung - von seinem Jugendprogramm anzusehen. Tatsächlich ist es möglich, DIP in den Mittelpunkt von Grotius frühem Programm zu stellen und sogar den frühen Grotius zum Kern aller nachfolgenden zu machen. Diese Interpretation sieht eine wesentliche Verbindung zwischen den frühen Handschriften im Konzept des Vertrauens, das einen politischen Individualismus unterstützt, den einige als epiku- 
reisch und andere als neo-stoisch bezeichnen. ${ }^{28}$ Wahrheit ist, was den Menschen mit Gott verbindet, und so wie Gott in seinen Beziehungen zu den Menschen transparent ist, sollte der Mensch in seinen Beziehungen ihm gegenüber und auch mit anderen Menschen transparent sein: et dici cogitata et dicta fieri (Meletius, 84). Dieser selbstverpflichtende Charakter von Vertrauen stattet den einzelnen Menschen sowohl mit einem Verständnis für Humanität als auch mit den Voraussetzungen für Soziabilität aus. Der Mensch schuldet sich diese Wahrhaftigkeit sowohl in seinen Beziehungen mit anderen Menschen als auch in seinen Beziehungen zu Gott und zur Religion. Nur im Kontext der Gesellschaft, dieser großen Stütze der Menschheit, akzeptieren wir Einschränkungen unserer Handlungsfreiheit und unserer Religionsfreiheit. Im öffentlichen Bereich müssen wir die Konventionen akzeptieren, die sich aus der Schaffung einer Gesellschaft und der Schaffung einer öffentlichen Kirche ergeben. Das Problem ist jedoch, dass es im Wesentlichen zwei Wege gibt, diese Einschränkungen zu verstehen. Der weise Mensch wird wissen, dass diese Einschränkungen nicht auf ihn abzielen, sondern auf die weniger Aufgeklärten, die der Führung bedürfen (und manchmal zum Narren gehalten werden müssen). Regierungskunst und reformierte Kirche schließen sich dort zusammen, wo die souveräne Macht der Herrscher als von Gott eingesetzt geheiligt ist. Daher akzeptiert der weise Mensch den Staat, in dem er lebt - und als guter Bürger verteidigt er sein Gemeinwesen. Der gewöhnliche Bürger ist in einer komplizierteren Lage. Die traditionelle Theorie betrachtete den Pöbel oder das gemeine Volk als aufsässig und unbeständig; zur Ordnung muss es manipuliert werden, anstatt erzogen oder aufgeklärt zu werden. Grotius entfernt sich von dieser klassischen Ansicht eines Justus Lipsius (1547-1606) über den gewöhnlichen Bürger und tritt ein für die essentielle Gleichheit aller Bürger sowie die zwangsläufige persönliche Verantwortung, Gottes Gnade anzunehmen. Eine notwendige Folgerung dieser Position ist, dass das Wesen von Religion und Regierung minimal definiert ist: während die Regierung für den Schutz von Eigentum und Frieden steht, erfordert die Religion nur Gott zu lieben und den Nächsten wie uns selbst.

In seiner Korrespondenz mit Grotius über den Meletius beschwerte sich Antonius Walaeus über die minimale Definition von Christentum in Grotius’ Wiedergabe der biblischen Botschaft. Hätte Grotius nicht zumindest Christus als Vermittler hinzufügen sollen? Nein, sagt Grotius, das brauche ich nicht, weil dogmata (wie Zivilgesetze) pragmatische, den Umständen gemäße Wahlmöglichkeiten sind und folglich nicht zu den Prinzipien (decreta) des Christentums gehören. Es gibt daher eine Spannung zwischen dem minimalistischen Programm und der Logik der (religiösen) Regierung. Letztere erfordert - zumindest gemäß der Tradition der Staatsräson - besondere, den Leidenschaften der gewöhnlichen Leute angepasste Techniken. Grotius ist sich dieser Tradition bewusst, schon im Parallelon, wo er die Römer in dieser Hinsicht verspottet. Er schient sie also nicht gutzuheißen.

$28 \quad$ Vgl. Tuck ?: Kap. 3; Blom/Winkel 2004. 
Anscheinend denkt Grotius, dass in dem Augenblick, wo der Mensch die Möglichkeit der Selbst-Referentialität erreicht hat (das, was der Mensch zu seinem Willen erklärt, ist für ihn selbst Gesetz; DIP regula III), der minimalistische Ansatz gerechtfertigt sei, auch wenn der gewöhnliche Bürger das zugrundeliegende Argument nicht versteht. Wenn wir annehmen können, dass die Bürger verstehen, dass das Vertrauen ein Gesetz für sich selbst ist - und dem Parallelon zufolge verstehen die Holländer dies, weil Vertrauen in ihrem Charakter liegt, - dann folgen im Prinzip alle anderen moralischen Verpflichtungen. Obwohl dies ein Kantischer Aspekt bei Grotius zu sein scheint, haben wir noch keine Unterscheidung zwischen noumenon und phenomenon, und Grotius scheint die praktischen Notwendigkeiten sozialer und religiöser Organisation außer Acht zu lassen (wie seine Reaktion auf Walaeus zeigte).

Die Selbstreferenz, die personales Handeln und Moralität gestaltet, spiegelt Gottes Kräfte wider. Dabei wird Religion (in ihrer minimalen Form) vorausgesetzt und eine Logik der Toleranz geschaffen, die nicht-fundamentale Fragen der Religion offen lässt. Grotius unterschied im Meletius bei nicht-christlichen Religionen zwischen den falschen und den weniger falschen. Erstere waren atheistische oder polytheistische Religionen, letztere waren die Natürliche Religion der Philosophen und die Religion des mosaischen Gesetzes. Die falschen Religionen leugnen, dass Gott allmächtig, allwissend und allgütig ist; die weniger falschen Religionen erkennen entweder die Erlösung von der Sünde nicht an oder sind abergläubisch. Für diese Religionen könnte es schon an sich schwierig sein, die Moralität von Vertrauen zu erkennen, aber das entbindet Christen nicht von ihrer eigenen Pflicht, vertrauenswürdig zu handeln. Selbst für den Umgang mit Häretikern gilt, pacta sunt servanda, eine Position, die in der frühneuzeitlichen Periode stark umstritten, aber für Grotius selbstverständlich war: da wir uns selbst Vertrauen schulden, können wir nicht je nach der Religion derer, mit denen wir es zu haben, unterschiedlich handeln.

Die Ironie der Geschichte war, dass gerade diejenigen, die - in ihrem Glauben an die Prädestination - das Handeln des Menschen nicht akzeptierten, Grotius’ Prinzip der Selbstdetermination veranschaulichen sollten. Gottes eigene Kinder, die Gefäße des Herrn verlangten ihr Recht, Geistliche ihrer Wahl zu bestimmen und widersetzten sich so den liberalen Vorstellungen der Regenten in den holländischen Städten. Ihre Argumente waren traditionell (d. h. orthodox), ${ }^{29}$ ihre Politik aber war moderner als ihnen vermutlich klar war. Die eigentlich nicht lösbaren Spannungen, die in Grotius' Luhmannschem System der Autopoiesis bestehen, wurden durch das Prinzip der Vorsehung umgangen, wobei diejenigen, die ihre Karten auf das Argument der Macht gesetzt hatten, kaltgestellt wurden.

$29 \quad$ In dieser Hinsicht ist die Debatte zwischen den Ministern Trigland und Uyttenbogaert aufschlussreich. Beide beanspruchten Orthodoxie für die Ansicht ihrer jeweiligen Seite über den freien Willen und die Prädestination. Innovation, wie auch Grotius’ häufiger Gebrauch der Beweisführung aus dem Altertum, war ihnen suspekt. 
Die Politische Theologie des Hugo Grotius, die dem Menschen vertraut, weil er Gott vertraut, begründet die moderne tolerante Gesellschaft und öffnet den Weg zur ersten Phase der Globalisierung. Im düsteren Zeitalter der Religionskriege wollte Grotius praktische Ergebnisse auf der Grundlage seines Verständnisses erreichen. In dem Bestreben, das Christentum wiederzuvereinigen, das für ihn nur ein einziges religiöses Erbe war, argumentierte er, dass der römische Papst nicht der Antichrist sei, für den Protestanten ihn gerne hielten. In seinem späteren Leben wurde er unzufrieden mit den Protestanten und zwar gerade wegen ihrer sektiererischen und unökumenischen Tendenzen. Dieselben Protestanten entdeckten Grotius im 18. Jahrhundert wieder und zwar gerade wegen seiner Politischen Theologie. Man mag jedoch bezweifeln, ob die zugrundeliegende theoretische Stoßkraft dieser neuen Politischen Theologie zu dieser Zeit völlig verstanden wurde. Das heraus-ragende Merkmal von Grotius’ Politischer Theologie ist, glaube ich, ihre Fähigkeit, die Vorstellung zu rechtfertigen, dass wir auch gegenüber Häretikern und Ungläubigen unsere Versprechen einhalten sollten. Indem er die Fähigkeit zur Universalität inmitten der großen Meinungsvielfalt anerkannte und deren Voraussetzungen deutlich machte, war es Grotius möglich, den Weg zum Religionsfrieden zu bereiten, wobei er an die inhärenten Eigenschaften religiöser Identitäten appellierte.

Bemerkenswert ist, dass die Grotianische Perspektive den Krieg klar gewann, obgleich er und seine Freunde die Schlacht von Dordtrecht 1618/19 deutlich verloren; nicht in dem Sinne, dass es der Staatenpartei gelang, 1650 die Herrschaft über Oranien zu erringen, auch nicht, weil die Liberalen in den deistischen Zeiten des 18. Jahrhunderts den Sieg davontrugen. Grotius gewann den Kampf um die tolerante Gesellschaft gerade weil es nicht einen einzigen Sieger gab, sondern alle Konfessionen lernen mussten, wie man sich an eine im Wesentlichen multi-religiöse Gesellschaft anpasst. Der große Streit um die Prädestination führte dazu, dass ihm der Stachel der entzweienden Kraft genommen wurde. Der Versuch der etablierten Kirche, den Status einer Kirche der Heiligen oder einer Staatskirche zu erhalten, war endgültig fehlgeschlagen. Da sie nichts davon war, musste die Reformierte Kirche nicht nur Lutheraner und Mennoniten, sondern auch Katholiken und Juden sowie Remonstraten als lebende Beispiele religiöser Vielfalt akzeptieren. Noch wichtiger war, dass die wechselnden Balancen in der religiösen Identität und politischen Fraktion eine Dynamik schufen, die, ins 19. Jahrhundert versetzt, zu völlig neuen religiösen und politischen Formierungen führten, ohne den religiösen und politischen Frieden zu gefährden. Im Rückblick betrachtet war das Ergebnis von Dordtrecht die Katharsis für turbulente Entwicklungen von Coornhert zu Arminius, eine Katharsis, die nicht Teil des Plans irgendeines Akteurs gewesen ist.

\section{Eine Anmerkung zur Autopoeisis}

An verschiedenen Stellen spricht Grotius vom perfekten Gemeinwesen, der respublica per- 
fecta. ${ }^{30}$ Dabei geht es im Wesentlichen um die Selbsterhaltung, die einerseits auf Selbstkontrolle und andererseits auf Selbstverteidigung verweist. Das Grundprinzip dieses Luhmannschen Begriffs ist, nehme ich an, ein Verlassen auf die Lebenswelt und folglich ein fundamentales Vertrauen auf Gemeinschaft. Mit anderen Worten, die Frage, die uns Grotius stellt, lautet: Wie können wir das kreative Potential selbststeuernder Gemeinschaften bewahren (d. h. das, was in anderen Ansätzen souveräne Herrscher sind, legibus absolutus, die Kontrolle über ihren status ausüben) in einer Welt, die dies nicht mehr für selbstverständlich hält?

Da die Frage der Selbst-Normativität für Grotius wesentlich war, wollte er die machtgestützten normativen Erklärungen der damaligen Weltmacht Spanien (und ihre scholastische Unterstützung kritisch bewerten, indem er die Selbst-Normativität des Individuums (die subjektiven Rechte) und der politischen Gemeinschaften (das Zivilrecht) einbrachte, ohne dabei den Wert einer interkonfessioneller Verständigung (das Völkerrecht) und die Prinzipien menschlicher Handlungen an sich (das Naturrecht) zu leugnen.

Grotius' Autopoeisis ist, meine ich, multidimensional:

1. Alle Normen setzen eine normative Entscheidung seitens der Individuen voraus. Der Wunsch, beständig und vertrauenswürdig zu sein - das ist die grotianische Idee des menschlichen Charakters: sich selbst treu zu bleiben.

2. Normen sind auch das Ergebnis menschlicher Anpassung an Umstände, was in der politischen Organisation am sichtbarsten wird: der Staat, in dem Normen vereinbart und folglich gerechtfertigt sind.

3. Normen müssen auch außerhalb der Grenzen des Staates anerkannt werden, wann immer es eine Übereinkunft unter den Völkern zu geben scheint: wenn z. B. alle Staaten ihren Bürgern verbieten, Süßigkeiten zu essen, dann gilt diese Norm auch für Individuen (oder andere Akteure) außerhalb des Einflussbereichs ihres eigenen Staates.

4. Die zugrundeliegende Frage ist: Wie können wir sowohl diese Bewegung hin zur Übereinkunft zwischen den Völkern (Normen in einer multi-kulturellen Welt) als auch ihre Unvollständigkeit erklären? Was sind die Gründe dafür, dass wir die Fähigkeit zur Übereinkunft haben, aber dennoch oft aus Eigeninteresse, Staatsräson oder sogar Bosheit handeln? Mit anderen Worten, was ist das genaue Wesen des Naturgesetzes oder die moralische Natur der Menschen unabhängig von dem, was sich aus ihren vertraglichen Beziehungen ergibt?

Eine Antwort auf die letzte Frage ist: die moralische Natur der Menschen ist gerade ihre Fähigkeit zu (1) und (3). Aber die Antwort ist unvollständig, denn Frage (4) fragt auch nach einer rechtfertigenden Metaphysik. Für Grotius war dies seine katholische (d. h. uni-

30 „Esse autem justam rempublicam, perfectam quamdam communitatem“ DIP, Kap. 13, 1. Siehe auch: „Nisi autem unaquaeque respublica belli gerendi haberet potestatem, non esset ad sui defensionem sufficiens. “DIP, Kap. 6. Ein weiteres Beispiel: „respublica civilis est perfecta et sibi sufficiens “ (De imperio summarum potestatum circa sacra, Ch. 1, § 14, zitiert aus Vitoria’s Relectiones, q. 7, § 8). 
versale) christliche Religion, von der er wahre Universalität verlangte, da er den Prozess moralischer Entwicklung für allgemeingültig hielt, selbst wenn man annehmen sollte (was ohne äußerste Verruchtheit nicht geschehen könnte), dass Gott nicht existiert.

Wenn wir keine befriedigende Antwort auf die Frage der zugrundeliegenden Metaphysik der moralischen Natur des Menschen haben, werden wir immer beim Eigeninteresse, also auch bei der Staatsräson enden. Der Grund dafür ist, dass die Antworten zu (1) und (3) nicht robust sind, wie: Was ist unser wahres Selbst? Was ist wirkliche Anpassung? Was ist wirkliche Völkerverständigung?

Der Grundgedanke der Autopoiesis (oder in diesem Fall small is beautiful) ist der grundsätzliche Glaube, dass wir uns in der Lebenswelt nicht selbst betrügen können. Hier ist jedoch die Frage: welche Lebenswelt? Und, wichtiger noch, wessen?

Noch öfter stoßen wir auf einen vorzeitigen Abbruch dieser Entwicklung:

(1) was für eine weitergehende Übereinkunft auch immer möglich sein könnte, ich habe das Recht, für mich selbst zu sorgen: Profit

(2) was auch immer usw., uns gehört die Zukunft (Vorsehung)

(3) was auch immer usw., wir können nicht auf diese Übereinkunft warten (Macht).

Der vorzeitige Abbruch der Wege der Gerechtigkeit in der Welt ist am stärksten, wenn alle drei Mechanismen funktionieren. Eine verfeinerte Version ist die, die besagt:

(1) Profit (für jeden), lasst uns den IMF gründen;

(2) Vorsehung (für jeden), lasst uns in Zivilgesellschaft und Multikulturismus investieren;

(3) Macht (für jeden), lasst uns eine UNO gründen.

Aber wie die menschliche Natur nun einmal ist, werden diese neuen Änderungen keine transparente moralische Ordnung mit sich bringen, und das Phänomen der Trittbrettfahrer und machiavellistischen Heuchler kann leicht zu einem Rückfall auf die erste Version vom vorzeitigen Abbruch führen.

Grotius’ Lektion ist vielleicht, dass moralischer Fortschritt in der Welt nur möglich ist, wenn wir (a) anerkennen, dass es nicht die simple Tatsache der Existenz Gottes ist, die die Welt zu einer moralischen macht; und (b) akzeptieren, dass wir dennoch eine moralische Metaphysik brauchen, um unser Verhalten unter (1) und (3) zu rechtfertigen und zu strukturieren.

\section{Literatur:}

Bakhuizen van den Brink, J. N., 1960: Documenta reformatoria: teksten uit de geschiedenis van kerk en theologie in de Nederlanden sedert de Hervorming. Kampen.

Blom, Hans W., 1996: Politieke theorieën in het eerste kwart van de zeventiende eeuw: 
Vaderland van aristocratische republiek naar gemengde staat. In: De Hollandse jaren van Hugo de Groot (1583-1621), Hrsg. v. H. J. M. Nellen und J. Trapman. Hilversum. Blom Hans W./Winkel, Laurens C., 2004/Hrsg.: Grotius and the Stoa. Assen.

Bonger, Henk, 2004: The life and work of Dirck Volkertszoon Coornhert. Übersetzt von Gerrit Voogt. Amsterdam.

Brandt, Geeraerdt, 1663: Verhaal van de reformatie, in en omtrent de Nederlanden met eenige aantekeningen en aanmerkingen. Amsterdam.

Breuer, Stefan, 1986: Sozialdisziplinierung. Probleme und Problemverlagerungen eines Konzepts bei Max Weber, Gerhard Oestreich und Michel Foucault. In: Soziale Sicherheit und soziale Disziplinierung. Beiträge zu einer historischen Theorie der Sozialpolitik. Hrsg. v. C. Sachße und F. Tennstedt. Frankfurt a. M.

Catterall, Douglas, 2002: Community without borders. Scots migrants and the changing face of power in the Dutch Republic, c. 1600-1700. Leiden.

Grotius, Hugo, 1871: Memorie van mijne intentien en notabele bejegeningen, In: Verhooren en andere bescheiden betreffende het rechtsgeding van Hugo de Groot. Hrsg. v. R. Fruin. Utrecht, S. 1-80.

Grotius, Hugo, 1984: De republica emendanda. Hrsg. v. A. Eyffinger u. a. In: Grotiana 5, S. 66-121.

Grotius, Hugo, 1988: Meletius, sive de iis quae inter Christianos conveniunt epistola. Übersetzt u. hrsg. v. G. H. M. Posthumus Meyjes. Leiden.

Grotius, Hugo, 2000: The antiquity of the Batavian Republic: with the notes by Petrus Scriverius. Hrsg. v. J. H. Waszink u. a. Assen.

Grotius, Hugo, 2001: De imperio summarum potestatum circa sacra. Hrsg. v. H.-J. van Dam. Kritische Edition mit Einführung, englischer Übersetzung und Kommentar(en). (Studies in the History of Christian Thought, 102). Leiden.

Israel, Jonathan, 1995: The Dutch Republic. Its rise, greatness, and fall 1477-1806, Oxford.

Lottes, Günther, 1992: Disziplin und Emanzipation. Das Sozialdisziplinierungskonzept und die Interpretation der frühneuzeitlichen Geschichte. In: Westfälische Forschungen 42, S. 63-74.

Prak, Maarten, 2002: Gouden eeuw: het raadsel van de Republiek. Nijmegen.

Trigland, Jacobus, 1650: Kerckelycke geschiedenissen, begrypende de swaere en bekommerlijcke geschillen, in de Vereenigde Nederlanden voor-gevallen, met derselver bestissinge: ende aenmerckingen op de Kerckelycke historie van Johannes Wtenbogaert: uyt autentycke stucken getrouwelijck vergadert, ende op begeerte der Zuyd en NoortHollantsche Synoden uytgegeven, tot nodige onderrichtinge. Leyden.

Tuck, Richard Rights of war and peace

Uytenbogaert, Johannes, 1610: Tractaet van 't ampt ende authoriteyt, eener hoogher christelicker overheydt in kerkelicke saecken. Den Haag.

Uytenbogaert, Johannes, 1646: De kerckelicke historie, vervatende verscheyden geden- 
ckwaerdige saecken, inde Christenheyt voorgevallen, van het jaer vierhondert af, tot in het jaer sestienhondert ende negenthien. Voornamelick in dese Geunieerde provintien. s.l. 